\title{
The economic burden of TNF $\alpha$ inhibitors and other biologic treatments in Norway
}

\author{
This article was published in the following Dove Press journal: \\ ClinicoEconomics and Outcomes Research \\ I8 March 201 I \\ Number of times this article has been viewed
}

\author{
Jan Norum' \\ Wenche Koldingsnes ${ }^{2}$ \\ Torfinn Aanes ${ }^{3}$ \\ Margaret Aarag Antonsen ${ }^{4}$ \\ Jon Florholmen ${ }^{5}$ \\ Masahide Kondo ${ }^{6}$ \\ 'Northern Norway Regional \\ Health Authority, Bodø, Norway; \\ ${ }^{2}$ Department of Rheumatology, \\ University Hospital of North Norway, \\ Tromsø, Norway; ${ }^{3}$ Drug Procurement \\ Cooperation, Oslo, Norway; ${ }^{4} \mathrm{Hospital}$ \\ Pharmacy of North Norway Trust, \\ Tromsø, Norway; ${ }^{5}$ Department of \\ Gastroenterology, University Hospital \\ of North Norway, Tromsø, Norway; \\ ${ }^{6}$ Department of Health Care Policy \\ and Management, Graduate School \\ of Comprehensive Human Sciences, \\ University of Tsukuba, Tsukuba, \\ Ibaraki, Japan
}

Correspondence: Jan Norum

Northern Norway Regional Health

Authority, N-8038 Bodø, Norway

Tel +4795404205

Fax +47 755 I290।

Email jan.norum@helse-nord.no
Objective: Costly biologic therapies have improved function and quality of life for patients suffering from rheumatic and inflammatory bowel diseases. In this survey, we aimed to document and analyze the costs.

Methods: In 2008, the total costs of tumor necrosis factor alpha inhibitors and other biologic agents in Norway were registered prospectively. In addition to costs, the pattern of use in the four Norwegian health regions was analyzed. The expenses were calculated in Norwegian krone and converted into Euros.

Results: The pattern of use was similar in all four regions, indicating that national guidelines are followed. Whereas the cost was similar in the southeast, western, and central regions, the expenses per thousand inhabitants were 1.56 times higher in the northern region. This indicates that patients in the northern region experienced a lower threshold for access to these drugs. The gap in costs between trusts within northern Norway was about to be closed. The Departments of Rheumatology and Gastroenterology had the highest consumption rates.

Conclusion: The total cost of biologic agents was significant. Northern Norway had among the highest consumption rates worldwide. This can partly be explained. Further exploration calls for a national registry for the use of these drugs.

Keywords: TNF $\alpha$ inhibitors, biologic agents, Norway, cost

\section{Introduction}

Over the last few years, patients suffering from rheumatoid arthritis (RA), ankylosing spondylitis (AS), psoriatic arthritis (PsA), inflammatory bowel disease (IBD), and skin diseases (psoriasis, pyoderma gangrenosum, Bechet's disease) have experienced a significant improvement in disease activity, development of damage, and quality of life due to new therapies. In parallel, health care administrators have experienced a significant increase in the cost of treatment due to the costly new biologic therapies tumor necrosis factor alpha (TNF $\alpha$ ) inhibitors and other biologic agents. Due to this challenge, in 2006, the Ministry of Health and Care Services and Norwegian Directorate of Health took an initiative to develop guidelines for the use of these drugs. In this setting, cost-effective treatment and similar access to therapy within the Norwegian regions were the main focus of the national health authorities. Furthermore, patients' access was based on specific selection criteria published as national guidelines. ${ }^{1-4}$ The guidelines (Table 1) were made by national groups with representatives from the Norwegian Medicines Agency; Norwegian Knowledge Centre for the Health Services; Norwegian associations for rheumatologists, dermatologists, and gastroenterologists; Norwegian Regional Health Authority trusts; 
Table I Recommendations on the use of tumor necrosis factor alpha inhibitors and other biologic agents in Norway as of January 2008 (www.lisnorway.no)

\begin{tabular}{lll}
\hline Disease & First choice & Second choice \\
\hline $\begin{array}{l}\text { Ankylosing spondylitis } \\
\text { Rheumatoid arthritis }\end{array}$ & Etanercept & Adalimumab \\
First line & Infliximab & Etanercept \\
Second line & Rituximab & \\
$\begin{array}{l}\text { Psoriatic disease } \\
\text { Ulcerous colitis and }\end{array}$ & Efalizumab & Etanercept \\
fistulating Crohn's disease & Infliximab & \\
Crohn's disease (serious) & Adalimumab & Infliximab \\
\hline
\end{tabular}

and Norwegian Directorate of Health. According to these guidelines, TNF $\alpha$ antagonists are generally considered as second- and/or third-line therapy. For example, patients suffering from RA are considered candidates for this therapy when the disease is active and they do not respond to disease-modifying antirheumatic drugs (DMARDs) (ie, methotrexate), antiflogistics, or intra-articular injection of steroids. A similar indication has been made for PsA and AS. Regular follow-ups are requested on a clinical as well as an economic basis, with the first check-up at 3 months. In cases of no clinical effect, TNF $\alpha$ antagonist therapy should be stopped within 3 months after initiation. Furthermore, the inhibitors are considered second- or thirdline therapy in patients suffering from Crohn's disease (CD), ulcerous colitis (UC), and/or psoriatic disease.

According to the order from the Department of Health, the four Norwegian Regional Health Authority trusts took over the financing of the TNF $\alpha$ inhibitors and other biologic therapy in June 2006. Consequently, the various pharmacies in Norway delivering these drugs to the patients (outpatient setting) and/or to the hospitals have their expenses refunded by the trusts. In northern Norway, the Regional Health Authority Trust constitutes four hospital trusts and one pharmacy trust. Due to the fact that hospital trusts now have to cover the expenses, they have a common concern about cost-effectiveness and whether national guidelines are followed and good clinical practice is achieved. Malpractice may be costly.

During the last few years, biologic therapies have caused a significant rise in the cost of therapy for rheumatic disorders and IBD. To compensate for this situation, national guidelines, summaries of present knowledge, and recommendations for therapy have been introduced. ${ }^{1-5}$ These recommendations list the first and second choice of treatment. In this survey, we aimed to clarify the medical cost of these drugs in all Norwegian health regions and further elucidate the status in the northern region. We aimed to clarify whether patients in the various regions had similar access to biologic treatment and discuss strategies for follow-up of this high-cost therapy.

\section{Materials and methods}

In the time period between January 1, 2008 and December 31,2008 , the total cost of TNF $\alpha$ inhibitors and other biologic agents in Norway was registered prospectively by the Drug Procurement Cooperation (www.lisnorway.no) (DPC). This database has a nationwide coverage, includes all biologic drugs refunded by the specialist health care team, and is run in cooperation by the four Norwegian regional health authorities. The DPC's main goal is to provide costly drugs to the hospital trusts at a low price by regularly announcing tenders for the supply. The expenses were calculated in Norwegian krone (NKr) and converted into Euros $(€)$ at a rate of $1 €=9.84 \mathrm{NKr}$ based on data from the National Bank of Norway on December 30, 2008 (www.norges-bank.no). The figures were calculated in absolute amounts spent and adjusted to the number of inhabitants in each region. The total costs should have been correlated to the number of patients in each region, but there were no national incidence data available.

We also accessed data from the Northern Norway Regional Health Authority concerning resources spent in the region on TNF $\alpha$ inhibitors and other biologic agents. Data from each hospital trust for 2007 and 2008 were analyzed. Furthermore, the accounts at the University Hospital of North Norway (UNN) Trust were analyzed for 10 months (January-October) in 2007 and 2008, respectively.

\section{Statistical analysis and authorization}

Microsoft ${ }^{\circledR}$ Office Excel 2007 (Microsoft Corporation, Redmond, WA, USA) was used for the database and calculations.

Data implemented were derived from national public resources and aggregated data. We had no access to any individual patient data, and approval from the Regional Committees for Medical and Health Research Ethics (REK) was not necessary.

\section{Results}

The total expenditure on the TNF $\alpha$ inhibitors and other biologic agents in the four Norwegian health regions is shown in Figure 1 and Table 2. The cost pattern of the various drugs employed was similar in all regions. A somewhat more frequent use of etanercept in the western region was observed initially, but the discrepancy was minimized 


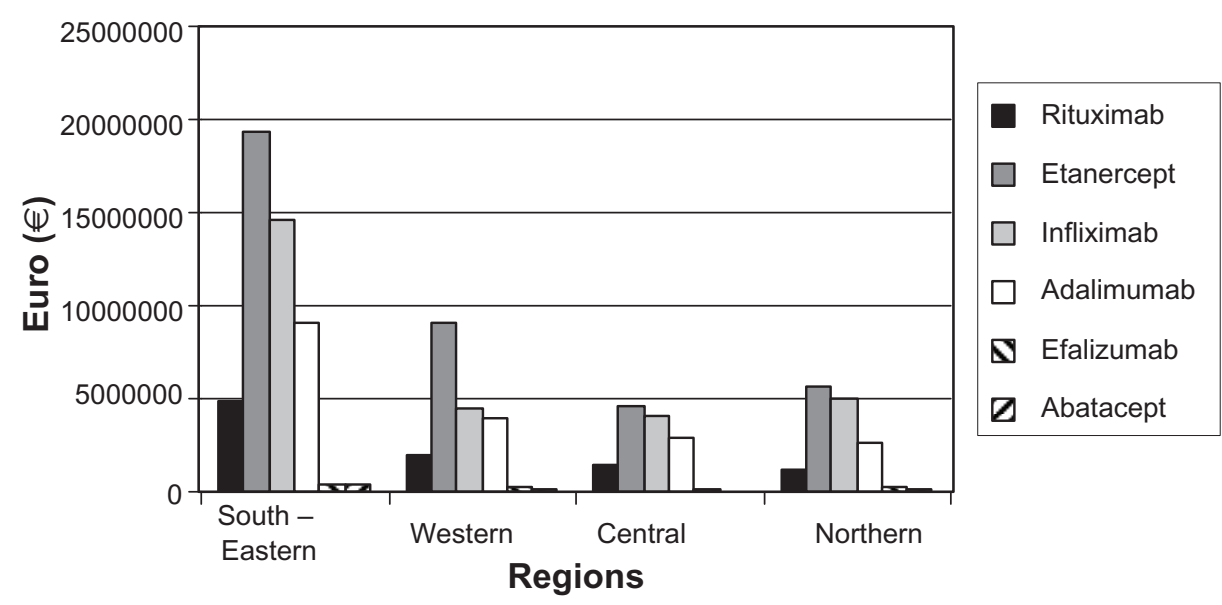

Figure I The figure illustrates the cost of tumor necrosis factor alpha inhibitors and other biologic agents in 2008 in the four Norwegian health regions. Costs are according to the 2008 pharmacy purchase price.

during the study period. The national consumption pattern disclosed corresponds well with the recommendations given by the Drug Procurement Cooperation (www.lisnorway.no) (Table 1). The economic resources spent in each region are illustrated in Table 2. The amount was significantly higher (1.56 times higher) in the northern region compared with the other regions. Employing the consumption rates revealed in the southeast, western, and central regions in northern Norway, the Northern Norway Regional Health Authority would have saved $€ 5.5$ million.

Looking at the figures from the accounts of the four hospital trusts within northern Norway (Figure 2), the costs increased by $26 \%-54 \%$ (mean $34.5 \%$ ) from 2007 to 2008 , indicating a harmonization of the costs within the region. The two southern located trusts experienced a major increase of costs (Helgeland Hospital Trust 54\%, Nordland Hospital Trust $42 \%$ ) compared with the others (UNN Trust 26\%, Finnmark Hospital Trust 32\%). The cost per inhabitant in 2008 was still highest at the UNN Trust, but the gap was about to be closed. The figures (cost/1000 inhabitants) were Helgeland Hospital Trust €4002, Nordland Hospital Trust $€ 4429$, UNN Trust $€ 5161$, and Finnmark Hospital

Table 2 The table shows the economic resources spent in 2008 on tumor necrosis factor alpha inhibitors and other biologic agents within Norway and its four health regions. Costs are in Euros $(€)$ and according to the 2008 pharmacy purchase price

\begin{tabular}{lllll}
\hline Region & Total cost $(\boldsymbol{\epsilon})$ & Inhabitants $^{\mathbf{a}}$ & ${\text { Cost }(\boldsymbol{\epsilon})^{\mathrm{b}}}^{\mathrm{b}}$ & Ratio \\
\hline Southeast & $48,658,883$ & $2,598,136$ & 18,728 & 0.91 \\
Western & $19,862,719$ & 967,471 & 20,531 & 0.99 \\
Central & $13,227,446$ & 653,290 & 20,247 & 0.98 \\
Northern & $14,892,173$ & 462,237 & 32,218 & 1.56 \\
Norway & $96,641,220$ & $4,681,134$ & 20,645 & 1.00 \\
\hline
\end{tabular}

Notes: a National figures as of January I, 2007. ${ }^{\mathrm{b}}$ Cost per 1000 inhabitants.
Trust $€ 3575$. These figures document minor differences in resources spent on TNF $\alpha$ inhibitors and other biologic agents within the northern region. Furthermore, people living "in the neighbourhood" of the university hospital seem to use these drugs more frequently than people living in other areas. However, this statement has to be handled with significant caution and should be considered within the framework that the UNN Trust serves as a regional university hospital for northern Norway and frequently takes part in research projects on new drugs. Inpatient therapy costs are taken care of by the hospital trust itself. Thus, patients referred from other areas of northern Norway and treated as inpatients will influence the balance of costs between hospitals. In a similar way, the Nordland Hospital Trust serves as a central hospital in the county of Nordland and supports the Helgeland Hospital Trust in its care of these patients.

Focusing on the departments at the UNN Trust, we disclosed the Departments of Rheumatology and Gastroenterology as the major consumers of these drugs. The Department of Gastroenterology spent $€ 758,346$ and $€ 1,022,181$ on these drugs during the first 10 months in 2007 and 2008, respectively (an annual increase of 35\%). The corresponding figures at the Department of Rheumatology were $€ 1,602,281$ and $€ 1,861,079$, indicating a $16 \%$ annual increase. These two departments accounted for three-quarters of all resources spent on TNF $\alpha$ inhibitors and other biologic agents at the UNN Trust.

\section{Discussion}

In this study, we have documented a similar pattern of use of various TNF $\alpha$ inhibitors and other biologic agents in all Norwegian health regions. The amount spent on these drugs in northern Norway was more than 1.5 times higher than in 


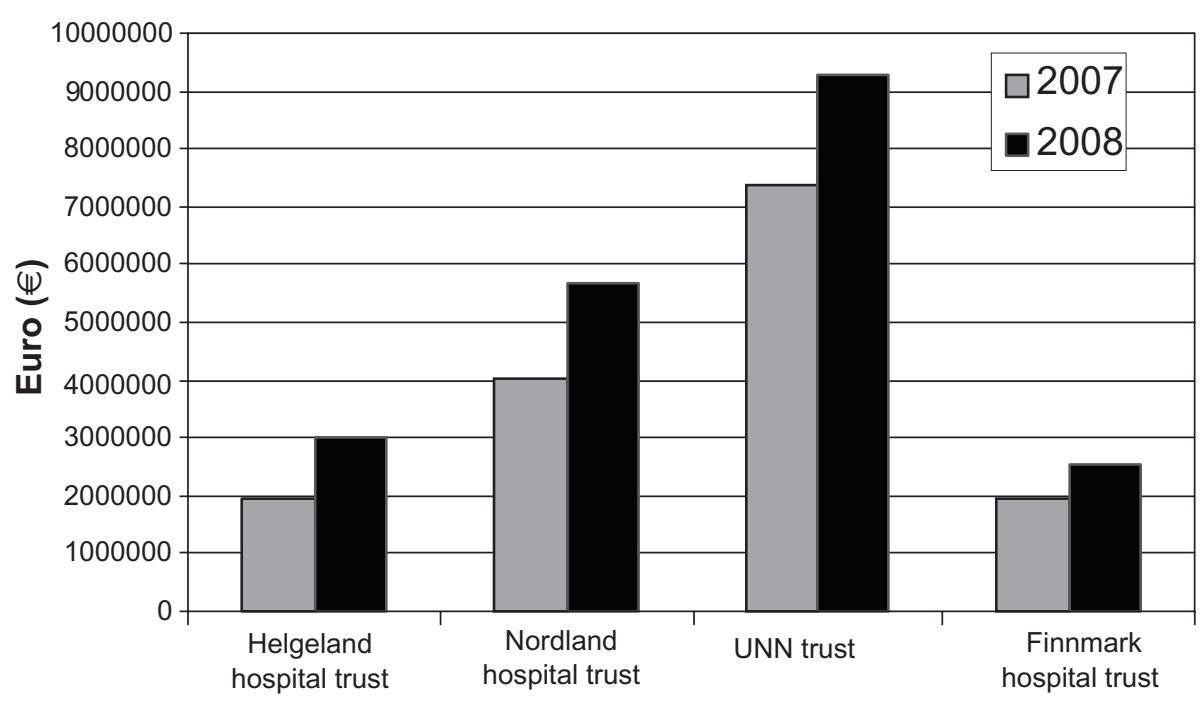

Hospital trusts

Figure 2 The figure shows the total economic resources spent on tumor necrosis factor alpha inhibitors and other biologic agents at the four hospital trusts in northern Norway in 2007 and 2008. The costs are according to the trusts' accounts and shown in Euros (€).

the other Norwegian health regions. A subgroup analysis revealed that most resources were spent in rheumatology and gastroenterology. The latter had the fastest growth of costs.

The similar pattern of use indicated that national guidelines were followed..$^{1-5}$ This was probably due to the fact that clinicians have taken an active part in the development of guidelines. The "obedience to guidelines" will be important when the new tender for the supply of biologic agents is announced. A common national strategy for the use of these drugs is of utmost importance (to achieve maximum value for money) when negotiating with pharmaceutical companies.

The cost-effectiveness of the biologic agents has been the focus of several investigators. ${ }^{6-14}$ According to Brennan et al ${ }^{6}$ and $\mathrm{Chen} \mathrm{et} \mathrm{al}^{7}$ figures in rheumatology (after RA patients have failed at least two traditional DMARDs) have been calculated at around $£ 24,000$ per quality-adjusted life-year (QALY). The incremental cost-effectiveness ratio (ICER) for etanercept has been reported to be lower ( $£ 24,000 / \mathrm{QALY}$ ) than the corresponding figures of adalimumab ( $£ 30,000 /$ QALY) and infliximab (£38,000/QALY), respectively. ${ }^{7}$ However, these figures should be viewed with caution, as drug prices vary between countries and over time.

Concerning AS, cost-effectiveness analyses have led to diverging results. ${ }^{10,11}$ McLeod et a $1^{10}$ concluded that none of the three anti-TNF $\alpha$ agents (adalimumab, etanercept, infliximab) was likely to be considered cost-effective. Bravo Vergel and Hawkins ${ }^{11}$ concluded that only etanercept (£26,361/ QALY) remained cost-effective.

The cost-effectiveness issue in the treatment of IBD has been the focus of at least four different groups. ${ }^{12-15}$ They all investigated TNF $\alpha$ inhibitors in the treatment of CD. We did not reveal any economic analysis involving UC. Arseneau et al ${ }^{12}$ calculated the cost/QALY between $\$ 355,450$ and $\$ 377,000$ and concluded that the ICER of infliximab for treating CD perianal fistulae over a 1-year period may not justify the higher cost. Clark et $\mathrm{al}^{13}$ compared infliximab and placebo. The ICER figures for chronic active CD were calculated as $£ 6700$, $£ 10,400$, and $£ 84,400$ /QALY, depending on whether it was a single-dose treatment, retreatment, or maintenance treatment, respectively. In fistulating CD, the cost/QALY was calculated to be $£ 102,000$ to $£ 123,000$ and $£ 82,000$ to $£ 96,000$ for the most favorable retreatment assumptions. Similar figures have been shown by others. ${ }^{13-15}$ All these reports documented that maintenance treatment using infliximab was not cost-effective in the case of $\mathrm{CD}$. In this setting, the annual increase of total costs (35\%) of TNF $\alpha$ inhibitors at the Department of Gastroenterology at the UNN Trust should be further analyzed. Most likely, this is caused by a new indication of UC, which together with $\mathrm{CD}$ is the main indication of anti-TNF in gastrointestinal diseases.

In northern Norway, the expenses per inhabitant were significantly higher than in all other regions. We did not reveal any increasing cost pattern from south to north within the northern region. Jönsson et $\mathrm{al}^{16}$ investigated international differences in the use of TNF $\alpha$ inhibitors and disclosed that the US had the most expensive use of these drugs, with Norway not far behind. Norway spent almost three times the average of the western European countries and Canada. The reason behind this has been difficult to elucidate. It has been suggested that a focus on the societal rather than a 
health care cost prospective may be one of the explanations. ${ }^{16}$ The notable sequelas of uncontrolled rheumatic inflammation include joint damage and functional disability, which, in turn, cause severe economic consequences not only to the patients and their families but also to society. Therefore, pharmacoeconomic analysis should take into account all relevant costs. ${ }^{17}$

A possible explanation for the significant spending of these drugs in northern Norway may be a higher incidence of IBD (personal communication from Professor Jon Florholmen, UNN) and rheumatologic disease. ${ }^{18,19}$ A somewhat higher incidence of AS has been reported in northern Norway. ${ }^{20}$ Moreover, AS is the disease with better survival on TNF inhibitors in comparison with RA and PsA. ${ }^{21}$ Looking at IBD, a difference between north and south in Europe has been reported, although the gap is being reduced as the incidence of IBD is increasing in southern Europe while it is stable in the north. ${ }^{22}$ However, known differences in prevalence and incidence cannot fully explain the different pattern of use within Norway. However, the clinical impression is that IBD is more frequent and more severe in the northern region than in the southern part of Norway (personal communication from Professor Jon Florholmen, UNN). Unpublished data from the Norwegian Disease-modifying Antirheumatic Drug Register on all disease-modifying treatment given to patients with RA, PsA, and AS have shown that the center representing north Norway (UNN) is not more liberal in starting treatment with TNF inhibitors than centers located in the southern and central regions. This is shown by the disease activity at onset of treatment, measured by Disease Activity Score 28, and by number of prior DMARDs at onset of TNF inhibitor treatment.

A third explanation could be that the institutions in the north are at the forefront of modern therapy in this setting and the time gap will be closed as the other regions change their practice. During the study period, we did not reveal any sign of a gap being closed, but the study period was short.

Furthermore, the distinctive characteristic of northern Norway may explain some of the differences in cost. This region constitutes half of the area of Norway but includes only $10 \%$ of the population. With a scattered population, cost of travel is significant. Keeping this fact in mind, clinicians may be less concerned about keeping patients off TNF $\alpha$ inhibitors because these drugs usually offer the best symptom control and consequently cost of travel may be avoided. An alternative treatment, repeated intra-articular injections by corticosteroids for patients with arthritis, would imply considerably more traveling in north Norway.
It could be speculated that the introduction of TNF $\alpha$ inhibitors may decrease consumption of other health care resources and therefore should be encouraged. This was not observed by Juillard-Condat et al. ${ }^{23}$ However, other investigators have shown savings in this setting. In a Dutch study, Welsing et $\mathrm{al}^{24}$ concluded that the greater effectiveness of the TNF $\alpha$ inhibitors reduced medical and nonmedical costs compared with usual treatment by about $16 \%$ and $33 \%$, respectively. Costs related to arthroplasty are significant in rheumatic disease. The Norwegian Orthopaedic Association started the Norwegian Arthroplasty Register in $1987 .{ }^{25}$ The register was extended to include arthroplasties in all joints in 1994. The aim of the registry was to detect inferior implants, cements, and operation techniques as early as possible. In the future, the need for arthroplasty and possible savings, following the introduction of biologic agents, should be focused on. An increase in total cost of disease due to TNF $\alpha$ inhibitors was established in a Danish study. ${ }^{26}$ This study concluded that the implementation of TNF $\alpha$ inhibitors in the treatment of RA would impose additional cost per year on the Danish health care service in the range of $€ 67$ million to $€ 188$ million for a progressive scenario.

\section{Conclusion}

Northern Norway has among the highest consumption rates of biologic agents worldwide. This can partly be explained. Health care budgets in Norway have been put under high pressure over the last few years, and resources have been allocated to achieve maximum value for money. The pressure has been even stronger during recent months due to the worldwide financial crisis. In this setting, raised expenses on drugs (such as TNF $\alpha$ inhibitors) have to be covered by savings in other settings. There is currently a need for health care administrators to get an overview of the use of TNF $\alpha$ inhibitors and other biologic agents in the treatment of IBD, skin diseases, and rheumatic disease. This situation calls for a national prescription database and/or a registry that makes it possible to compare the estimated annual cost and number of patients treated, time on therapy, actual cost per patient, and number of patients with a prescription for a defined time period. The registry should also include data on disease activity and damage, quality of life, and working capacity and disability. Especially in the care of IBD, maintenance therapy must be avoided from a cost-effectiveness point of view.

\section{Acknowledgments}

We thank colleagues at the Nordland Hospital, University Hospital of North Norway, and Hospital Pharmacy Trust for 
sharing their experience during a seminar on this topic in late October 2008. Their comments were of great value to us. The assistance given by Arnborg Ramsvik at the Northern Norway Regional Health Authority in Bodø is also greatly appreciated.

\section{Disclosure}

The authors report no conflicts of interest in this work.

\section{References}

1. Arentz-Hansen H, Granum L, Gulseth HC, et al. TNF Inhibitors for Rheumatic Diseases. Oslo, Norwegian Knowledge Centre for the Health Services, report 12; 2006.

2. Arentz-Hansen H, Palm Ø, Norderhaug IN, et al. TNF Inhibitors for Rheumatic Diseases (Part 2). Effect and Side Effects. Oslo, Norwegian Knowledge Centre for the Health Services, report 2; 2007.

3. Moen E, Neilson AR, Aaserud M, et al. TNF Inhibitors for Rheumatic Diseases (Part 3). Health Economics. Oslo, Norwegian Knowledge Centre for the Health Services, report 16; 2007.

4. Sæterdal I, Mørk NJ, Dalaker M, et al. TNF Inhibitors and Efalizumab for the Treatment of Skin Diseases. Oslo, Norwegian Knowledge Centre for the Health Services, report 15; 2007.

5. Ringerike T, Elvsaas IKØ, Coll P, et al. TNF $\alpha$-inhibitors in Inflammatory Bowel Disease. Oslo, Norwegian Knowledge Centre for the Health Services, report 32; 2008.

6. Brennan A, Bansback N, Nixon R, et al. Modelling the cost effectiveness of TNF- $\alpha$ antagonists in the management of rheumatoid arthritis: results from the British Society for Rheumatology Biologics Registry. Rheumatology. 2007;46:1345-1354.

7. Chen YF, Jobanputra P, Barton P, et al. A systematic review of the effectiveness of adalimumab, etanercept and infliximab for the treatment of rheumatoid arthritis in adults and an economic evaluation of their cost-effectiveness. Health Technol Assess. 2006;10(42):1-229.

8. Doan QV, Chiou CF, Dubois RW, et al. Review of eight pharmaeconomic studies of the value of biologic DMARDs (adalimumab, etanercept, and infliximab) in the mangament of rheumatoid arthritis. $J$ Manag Care Pharm. 2006;12:555-569.

9. Wu E, Chen L, Birnbaum H, et al. Cost of care for patients with rheumatoid arthirits receiving TNF-antagonist therapy using claims data. Curr Med Res Opin. 2007;23:1749-1759.

10. McLeod C, Bagust A, Boland A, et al. Adalimumab, etanercept and infliximab for the treatment of ankylosing spondylitis: a systematic review and economic evaluation. Health Technol Assess. 2007;11(28):1-158.

11. Bravo Vergel Y, Hawkins NS. The cost-effectiveness of etanercept and infliximab for the treatment of patients with psoriatic arthritis. Rheumatology. 2007;46:1729-1735.
12. Arseneau KO, Cohn SM, Cominelli F, et al. Cost utility of initial medical management for Crohn's disease perioanal fistula. Gastroenterology. 2001;120:1640-1656.

13. Clark W, Raftery J, Song F, et al. Systematic review and economic evaluation of the effectiveness of infliximab for the treatment of Crohn's disease. Health Technol Assess. 2003;7:1-67.

14. Jaisson-Hot I, Flourie B, Descos L, et al. Management for severe Crohn's disease: a lifetime cost-utility analysis. Int JTechnol Assess Health Care. 2004;20:274-279.

15. Marshall J, Blackhouse G, Goeree R, et al. Infliximab Management for the Treatment of Crohn's Disease: a Systematic Review and Cost-utility Analysis. Ottawa: Canadian Coordinating Office for Health Technology Assessment (CCOHTA); Technology report No. 24; 2002.

16. Jönsson B, Kobelt G, Smolen J, et al. The burden of rheumatoid arthritis and access to treatment uptake of new therapies. Eur J Health Econ. 2008;8:61-86.

17. Kavanaugh A. Economic consequences of established rheumatoid arthritis and its treatment. Best Pract Res Clin Rheum. 2007;21: 929-942.

18. Koldingsnes W, Nossent HC. Epidemiology of ANCA associated vasulitis. Nor Epidem. 2008;18:37-48.

19. Watts RA, Lane SE, Scott DG, et al. Epidemiology of vasculitis in Europe. Ann Rheum Dis. 2001;60:1156-1157.

20. Bakland G, Nossent HC, Gran JT, et al. Incidence and prevalence of ankylosing spondylitis in northern Norway. Arthritis Rheum. 2005;53: $850-855$.

21. Heiberg MS, Koldingsnes W, Mikkelsen K, et al. The comparative oneyear performance of anti-tumor necrosis factor alpha drugs in patients with rheumatoid arthritis, psoriatic arthritis, and ankylosing spondylitis: results from a longitudinal, observational, multicenter study. Arthritis Rheum. 2008;59:234-240.

22. Shivananda S, Lennard-Jones J, Logan R, et al. Incidence of inflammatory bowel disease across Europe: is there a difference between north and south? Results of the European Collaborative Study on Inflammatory Bowel Disease (EC-IBD). Gut. 1996;39:690-697.

23. Juillard-Condat B, Copnstantin A, Cambon-Thompson A, et al. Impact of etanercept on the costs of theumatoid arthritis (RA): results from a French observational study. Joint Bone Spine. 2008;75:25-28.

24. Welsing PMJ, Severens JL, Hartman M, et al. Modeling the 5-year cost effectiveness of treatment strategies including tumour necrosis factorblocking agents and leflunomide for treating rheumatoid arthritis in the Netherlands. Arthritis Rheum. 2004;51:964-973.

25. Lie SA, Vollset SE, Furnes O, et al. The Norwegian Arthroplasty Register: beneficial for patients and for the Norwegian health care system. Nor J Epidem. 2004;14:57-63.

26. Sørensen J, Andersen LS. The case of tumour necrosis factor-alpha inhibitors in the treatment of rheumatoid arthritis: a budget impact analysis. Pharm Econ. 2005;23:289-298.
ClinicoEconomics and Outcomes Research

\section{Publish your work in this journal}

ClinicoEconomics \& Outcomes Research is an international, peerreviewed open-access journal focusing on Health Technology Assessment, Pharmacoeconomics and Outcomes Research in the areas of diagnosis, medical devices, and clinical, surgical and pharmacological intervention. The economic impact of health policy and health systems

\section{Dovepress}

organization also constitute important areas of coverage. The manuscript management system is completely online and includes a very quick and fair peer-review system, which is all easy to use. Visit http://www.dovepress.com/testimonials.php to read real quotes from published authors. 